Stable Isotope Techniques for

the Assessment of Host and

Microbiota Response During

Gastrointestinal Dysfunction

Journal Article

Author(s):

Butler, Ross N.; Kosek, Margaret; Krebs, Nancy F.; Loechl, Cornelia U.; Loy, Alexander; Owino, Victor O.; Zimmermann, Michael B.; Morrison, Douglas J.

Publication date:

2017-01

Permanent link:

https://doi.org/10.3929/ethz-b-000128266

Rights / license:

Creative Commons Attribution 4.0 International

Originally published in:

Journal of Pediatric Gastroenterology and Nutrition 64(1), https://doi.org/10.1097/MPG.0000000000001373 


\title{
Stable Isotope Techniques for the Assessment of Host and Microbiota Response During Gastrointestinal Dysfunction
}

\author{
${ }^{*}$ Ross N. Butler, ${ }^{\dagger}$ Margaret Kosek, ${ }^{\ddagger}$ Nancy F. Krebs, ${ }^{\S}$ Cornelia U. Loechl, ${ }^{\prime}$ Alexander Loy, \\ ${ }^{\S}$ Victor O. Owino, "Michael B. Zimmermann, and ${ }^{\#}$ Douglas J. Morrison
}

\begin{abstract}
The International Atomic Energy Agency convened a technical meeting on environmental enteric dysfunction (EED) in Vienna (October 28-30, 2015; https://nucleus.iaea.org/HHW/Nutrition/EED_Technical_Meeting/index.html) to bring together international experts in the fields of EED, nutrition, and stable isotope technologies. Advances in stable isotope-labeling techniques open up new possibilities to improve our understanding of gastrointestinal dysfunction and the role of the microbiota in host health. In the context of EED, little is known about the role gut dysfunction may play in macro- and micronutrient bioavailability and requirements and what the consequences may be for nutritional status and linear growth. Stable isotope labeling techniques have been used to assess intestinal mucosal injury and barrier function, carbohydrate digestion and fermentation, protein-derived amino acid bioavailability and requirements, micronutrient bioavailability and to track microbe-microbe and microbe-host interactions at the single cell level. The noninvasive nature of stable isotope technologies potentially allow for low-hazard, field-deployable tests of gut dysfunction that are applicable across all age groups. The purpose of this review is to assess the state-of-the-art use of stable isotope technologies and to provide a perspective on where these technologies can be exploited to further our understanding of gut dysfunction in EED.
\end{abstract}

Key Words: environmental enteric dysfunction, gut dysfunction, gut microbiota, malnutrition, stable isotopes

(JPGN 2017;64: 8-14)

$\mathrm{E}$ nvironmental enteric dysfunction (EED) is thought to be a major contributing cause of the failure of nutritional interventions, be they based on micronutrient, macronutrient, and combined supplementation with behavioral change to normalize postnatal linear growth in populations living in poverty (conceptualized in Fig. 1 adapted from (1)). EED, among other factors, is the result of multiple and continuous infections even in the absence of diarrhea or well-defined clinical illness. It is posited to lead to local intestinal inflammation, altered intestinal permeability with subsequent bacterial translocation and immune activation. Functional aberrations

Received April 22, 2016; accepted August 2, 2016

From the *School of Pharmacy and Medical Sciences, Division of Health Sciences, University of South Australia, Adelaide, Australia, the †Bloomberg School of Public Health, John Hopkins University, Baltimore, MD, the $\ddagger$ Department of Pediatrics, School of Medicine, University of Colorado, Aurora, the $\$$ Nutrition and Health-Related Environmental Studies Section, Division of Human Health, International Atomic Energy Agency, the IIDivision of Microbial Ecology, Department of Microbial and Ecosystem Science, Research Network Chemistry meets Microbiology, University of Vienna, Vienna, Austria, the Institute of Food, Nutrition and Health, Department of Health Sciences and Technology, ETH Zürich, Zurich, Switzerland, and the \#Scottish Universities Environmental Research Centre, University of Glasgow, East Kilbride, Scotland, UK.

Address correspondence and reprint requests to Dr Douglas J. Morrison, Stable Isotope Biochemistry Laboratory, Scottish Universities Environmental Research Centre, University of Glasgow, Rankine Ave, East Kilbride, Glasgow G75 0QF, UK (e-mail: douglas.morrison@glasgow.ac.uk).

\section{What Is Known}

- Linear growth retardation (stunting) currently affects 165 million children worldwide.

- Nutritional interventions have had only moderate effects on linear growth.

- Environmental enteric dysfunction is thought to be a major contributing cause of the failure of nutritional interventions.

\section{What Is New}

- There is a lack of functional biomarkers to assess gut dysfunction in environmental enteric dysfunction. Biomarkers of nutrient digestion and absorption capacity, gut permeability, and gut and systemic inflammation may allow a greater understanding of the role of environmental enteric dysfunction in nutritional interventions. Stable isotope techniques have the potential to assess multiple aspects of gut dysfunction in environmental enteric dysfunction.

in EED may include a reduced ability to digest macronutrients, reduced capacity to absorb essential nutrients, and disturbances in micronutrient requirements. The role of the small intestinal microbiota is unclear but clearly is an important factor in the development and pathogenesis of EED (2). In EED, the state of chronic immune activation compromises intestinal function and host metabolism in a way that derails normal prescribed linear growth patterns in affected populations.

Work at the Stable Isotope Biochemistry Laboratory, SUERC is funded in part by BBSRC (BB/L004259/1, BB/L025418/1). A.L. is supported by the Vienna Science and Technology Fund (WWTF, project LS12-001) and the Austrian Science Fund (FWF, project I 2320-B22). The IAEA convened a Technical Meeting on EED in Vienna in which all the authors participated.

The authors report no conflicts of interest.

Copyright (C) 2016 by European Society for Pediatric Gastroenterology, Hepatology, and Nutrition and North American Society for Pediatric Gastroenterology, Hepatology, and Nutrition. This is an open access article distributed under the Creative Commons Attribution License 4.0 (CCBY), which permits unrestricted use, distribution, and reproduction in any medium, provided the original work is properly cited.

DOI: $10.1097 / M P G .0000000000001373$ 


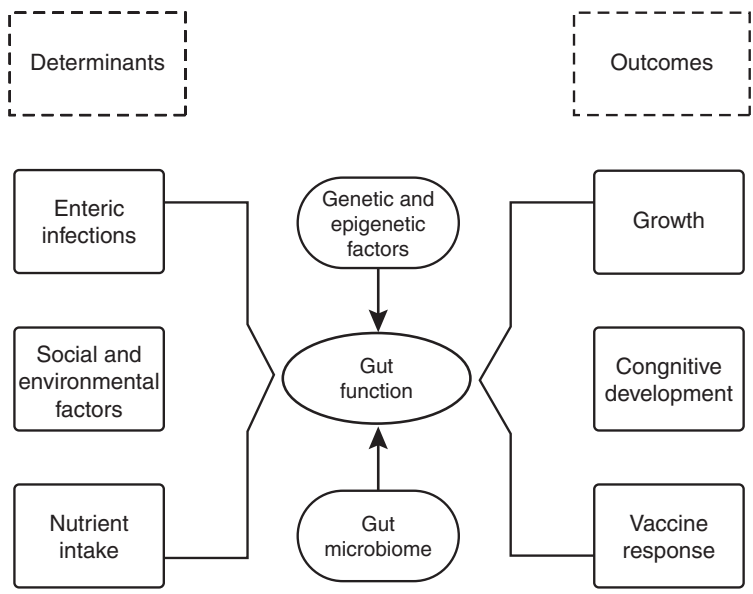

FIGURE 1. Repeated enteric infections coupled with altered mucosal immune responses and macronutrient/micronutrient absorption and availability are major determinants of gut dysfunction observed in environmental enteric dysfunction (EED). The role of the gut microbiome requires further investigation. Together, these may be important drivers of the outcomes observed in EED such as growth faltering, reduced vaccine response, and impairments in cognitive development.

Stunting, defined as linear growth (height-for-age) 2 standard deviations below the population median growth curve, currently affects $25.7 \%$ of the world's children; the total number of affected individuals being 165 million (3). Despite this burden, controlled interventions including the provision of food in food insecure settings, and the provision of education regarding feeding practices have had only moderate effects on linear growth (4). EED is thought to be one of the major causes of the failure of nutritional interventions in children at risk from stunting (5). The validation of this theory is however currently limited by a lack of reliable assays to measure some of these key parameters that are thought to be deranged in EED.

Identification of better biomarkers and delineation of the key biological pathways may also guide better-targeted interventions. Although markers of systemic inflammation are plentiful and well described (6), markers of intestinal permeability, nutrient absorption, enterocyte metabolic capacity, intestinal inflammation, and intestinal regeneration and repair are extremely limited. This lack of functional measurements severely limits our understanding of the intestinal processes that control nutrient bioavailability and inflammation and our ability to focus on effective interventions. Here, we review and discuss the potential of available stable isotope techniques as non-/less-invasive and safe tools for advanced diagnosis and research of gastrointestinal dysfunction.

\section{PRINCIPLE OF USING STABLE ISOTOPES IN GASTROENTEROLOGY}

The basic principle of all stable isotope techniques in gastroenterology is to administrate a stable isotope-labeled compound to the body (ie, orally, rectally, or intravenously) in "trace" amounts to minimally disturb normal physiology, and to subsequently track the fate of the compound or its catabolic products in breath, tissue, feces, urine, and/or blood (7). The route of administration and type of isotope label and compound essentially determine which gastrointestinal function is assessed. Stable isotope techniques are often used to determine general epithelial function such as absorption and permeability. They, however, can also rather precisely measure specific metabolic features in the intestinal tract such as uptake of a defined micronutrient or a defined physiological property of intestinal microbiota members metabolizing the administered compound. The attraction of stable isotope-based technologies in EED is their potential for noninvasive diagnosis in field research settings to assess a wide assortment of different components of gut physiology and function. By measuring the magnitude of deviation from normal physiology in different epidemiologic contexts, the underlying nature and extent of pathology that underscores gut dysfunction in EED could be elucidated facilitating the development of effective diagnostic tests and interventions.

\section{BREATH TESTS AND SMALL INTESTINAL FUNCTION}

Breath tests are characterized by their noninvasive technology and as such are ideal for both diagnostic and longitudinal studies. The test performance characteristics are particularly wellsuited for studying children as testing is painless and noninvasive (8). The most robust, safe, sensitive, and specific stable isotope breath test devised is the ${ }^{13} \mathrm{C}$ urea breath test for the diagnosis and monitoring of Helicobacter pylori (Hp). It has repeatedly been shown to have $>95 \%$ sensitivity and specificity (9). There are some intrinsic advantages that favor this. First, when $\mathrm{Hp}$ is present it is usually the dominant microorganism in the low $\mathrm{pH}$ environment of the stomach and may affect linear growth (10). By thriving in the mucosa of the stomach, $\mathrm{Hp}$ is also close to the site of oral tracer administration, leading to rapid delivery of the tracer bolus to the site of infection. As the tracer target moves more distal in the intestine, complex delivery formulation may be needed to allow for site-directed tracer delivery, and there may be variations in transit time that reduce sensitivity and specificity of the test.

Therefore, the measurement of functional characteristics in gastrointestinal tract regions distal to the stomach presents greater challenges with respect to targeting functional characteristics, epithelial damage, and barrier integrity and specifically targeting pathogens $(11,12)$. Several stable isotope breath tests for assessing gastric emptying have been designed and validated against scintigraphic methods $(13,14)$. These tests have also been combined with nonabsorbable carbohydrates, such as lactulose, using $\mathrm{H}_{2}$ measurements in breath to determine orocecal transit time of a particular meal (15). This in turn gives an indication and allows calculation of small intestine residency time. Less attention has been given to interrogating the patency of the small intestinal mucosa. A notable exception is the assessment of lactase deficiency or lactose malabsorption and intolerance (16). This has traditionally been detected using a $\mathrm{H}_{2}$ breath test or with a combined $\mathrm{H}_{2} /{ }^{13} \mathrm{CO}_{2}$ breath test (17).

Only a small percentage of individuals exhibit a genetically determined sucrase deficiency, much less than the global $70 \%$ to $90 \%$ prevalence for lactase deficiency (18). This raises the possibility of using a ${ }^{13} \mathrm{C}$ sucrose breath test (SBT) as a noninvasive reporter for detecting small intestinal villus dysfunction and damage, by targeting sucrase activity as the surrogate for quantifying the maturity of the absorptive capacity of the epithelium $(19,20)$. A villus atrophy induced by chemotherapy is a common occurrence, but ethical practice precludes endoscopy to assess the severity and to thus monitor any ameliorating interventions. The SBT has been reported in animal models and in childhood cancer chemotherapy and appears to act as a surrogate marker for small intestinal villus dysfunction and damage $(21-23)$.

Other settings where significant small intestinal damage occurs include rotavirus infection, Giardia lamblia infestation, celiac disease, and the endemic spectrum of EED. In many of these diseases and disorders, the degree of absorptive impairment is 
not known nor easily measurable; thus, its contribution to health and linear growth in childhood is not fully understood. Preliminary studies in children with acute diarrhea have shown lowered SBT response that improves as disease resolution occurs (24). In infants with EED, resolution of the small intestinal impairment in the same time frame, however, did not occur. Correspondingly, nor did the severity of diarrhea in these children (25).

Multiple isotope labels, targeted delivery, and additional stable isotope end-points, including breath ${ }^{13} \mathrm{CO}_{2}$, will potentially move this strategy forward for understanding gut dysfunction in EED.

\section{STABLE ISOTOPES, MACRONUTRIENT BIOAVAILABILITY, AND HOST RESPONSE}

Classical stable isotope-dilution techniques, which use steady-state tracer infusion protocols, have become an essential tool for determining metabolite flux in humans (26). They, however, only focus on a limited number of targeted metabolites and are unsuitable for investigations in young children because they involve extended tracer infusions and serial blood and/or tissue sampling. Intrinsic labeling of macronutrients for human feeding studies allows for an integrative assessment of nutrient bioavailability. The photosynthetic pathways of carbon sequestration in plants $(\mathrm{C} 3$ vs $\mathrm{C} 4)$ provide natural isotopic carbon-13 $\left({ }^{13} \mathrm{C}\right)$ enrichment in $\mathrm{C} 4$ plant material that is sufficient for measurement by isotope ratio mass spectrometry (27). C4 plant-derived carbohydrates have been allowed assessment of liver glycogen oxidation (28), starch digestion, and exogenous glucose production in adults $(29,30)$ and children (31). This approach is however limited by the low signal to background ${ }^{13} \mathrm{C}$ abundance. Studies using isotope labeling (enrichment) techniques have largely overcome these challenges. This experimental approach is exemplarily outlined for stable isotope-labeled, plant-derived dietary compounds in Figure 2. Isotope labeling has been used to describe quantitative exogenous glucose production and insulin sensitivity from native plant-derived starches (32-34). Beyond starch, ${ }^{13} \mathrm{C}$ labeling has been used to determine quantitatively short chain fatty acids (SCFA) production

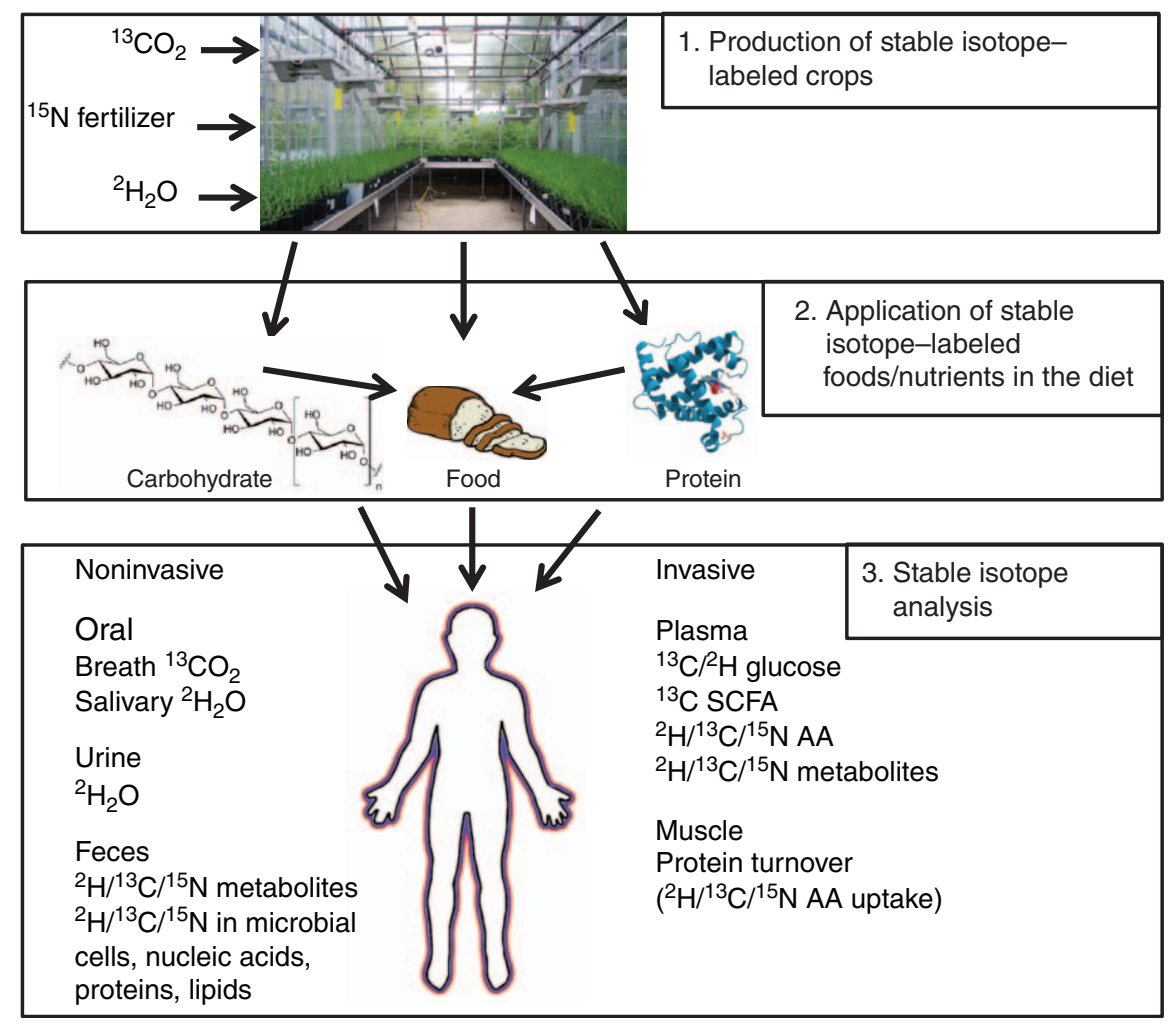

FIGURE 2. The 3 domains of a human stable isotope-labeling experiment using labeled macronutrients. Stable isotope labeling of macronutrients from plant sources has been achieved by both ${ }^{13} \mathrm{CO}_{2}$ enrichment of the plant atmosphere, use of ${ }^{15} \mathrm{~N}$ (nitrate, ammonium) fertilizers or ${ }^{2} \mathrm{H}_{2} \mathrm{O}$ labeling of plant feed water. Deuterium labeling lends itself to both low and highly enriched plant products, whereas carbon labeling is mostly (but not exclusively) restricted to low-enriched products. The labeling strategy has consequences for the technologies required to measure isotopic enrichment in target metabolites. Highly enriched metabolites ( $>1$ atom percent excess) are amenable to "organic" mass spectrometry and NMR. Low-enriched metabolites are largely restricted to isotope ratio mass spectrometry approaches. Once a labeling protocol has been undertaken, the plant can be used whole, or fractionated into macronutrients and incorporated into foods (the food matrix remaining unlabeled but target macronutrients labeled within the food). Once ingested, the analysis required depends on the question being asked. If rate and extent of oxidation are the only requirements (as in ${ }^{13} \mathrm{C}$ breath tests), collection of expired breath ${ }^{13} \mathrm{CO}_{2}$ over time is sufficient. If molecular information is required about metabolites from digestion and absorption of a labeled macronutrient, then compound-specific isotope analysis is necessary, often through serial blood sampling to gather time-course information. Such information may also be available through urine metabolite excretion. In order to derive true molecular flux information, a second tracer administered (orally or intravenously) in a known quantity may sometimes be required to account for the unknown fraction of labeled metabolites entering a biological pool from macronutrient digestion and absorption. Finally fecal microbiota isotope sequestration yields information on nutrient uptake and microbial activity specific to the labeled substrate. 
from inulin in vivo (35), and the extent of carbohydrate oxidation from $\beta$-glucan-enriched barley (36). These tools uniquely allow a full understanding of macronutrient bioavailability, requirements, and metabolism and potentially provide new mechanistic insights into how carbohydrate requirements and metabolism are altered in EED.

Of considerable interest in EED is the bioavailability of, and nutritional requirements for, protein-derived amino acids. Energy, protein, and usable protein availability are negatively associated with stunting (37). Recent evidence has demonstrated reduced serum essential amino acids in stunted children (38). What role EED plays in altering protein digestion and amino acid absorption and use is unclear at the present time. The limitations of current techniques to assess protein quality and amino acid requirements have been extensively reviewed elsewhere $(39,40)$. ${ }^{15} \mathrm{~N}$-labeled proteins have been used to determine net postprandial protein use $(41,42)$, by measuring of the kinetics of dietary $\mathrm{N}$ appearance in ileal contents, plasma proteins, plasma free amino acids, body and urinary urea, and urinary ammonia in a 13-compartment, 21-parameter model (43). The complexity of the technique means it is unlikely to be widely adopted for routine applications (39). In children, ${ }^{13} \mathrm{CO}_{2}$ production has been used as an index of bioavailability from oxidation of protein-bound indicator ${ }^{13} \mathrm{C}$ labeled amino acids whereby the extent of amino acid oxidation is inversely related to amino acid uptake through protein synthesis (44). Amino acid infusion studies using animals to intrinsically label-specific amino acids in milk and meat protein have shown a dose-response of de novo muscle protein synthesis to whey protein in human feeding studies (45), and that minced beef increases postprandial protein retention compared with beef steak (46). A combined dual stable isotope study using ${ }^{15} \mathrm{~N}$-labeled Spirulina protein and ${ }^{2} \mathrm{H}-$ phenylalanine has demonstrated that protein digestibility is severely compromised in patients with cystic fibrosis (47). Of significant potential is intrinsic labeling of cereal, legume, and animal-derived protein with ${ }^{2} \mathrm{H}$, in combination with ${ }^{13} \mathrm{C}$-labeled amino acids from a (predigested) crystalline amino acid mixture having the same composition as the intact protein to assess amino acid bioavailability $(48,49)$. In EED, this approach has the potential to assess amino acid bioavailability and requirements, taking into account directly the disturbances in digestion and absorption. Finally, intrinsic labeling of amino acids in humans using ${ }^{2} \mathrm{H}_{2} \mathrm{O}$ has been used to determine the role of diet and disease on whole-body and tissue-specific protein synthesis (50-52).

Isotope studies on lipid use related to gut dysfunction have largely been focused on the efficiency of fat digestion in the intestine. The use of ${ }^{13} \mathrm{C}$-labeled triglyceride combined with ${ }^{13} \mathrm{CO}_{2}$ appearance in breath has been used to assess pancreatic exocrine insufficiency (53), efficacy of pancreatic enzyme supplementation in disease (54), the effects of gastrectomy on fat digestion (55), and to determine how oral fat exposure, enteral lipid metabolism impacts upon postprandial lipemia (56).

The power of stable isotopes to trace macronutrient assimilation is unparalleled because they can be used in physiologically relevant settings. The challenge is to develop methodologies that are minimally invasive while yielding maximum information on how EED affects the digestion, absorption, and the use of the major macronutrients.

\section{MICRONUTRIENT ABSORPTION AND BIOAVAILABILITY}

Zinc and iron are 2 micronutrients of particular importance for investigations of etiology and therapy for EED. Deficiencies of each nutrient are common, and disrupted absorption and homeostasis are considered to be likely. Stable isotope studies have been widely applied to examine bioavailability of each of these nutrients from local diets, fortified and bio-fortified foods, and from supplements in vulnerable populations. Great potential exists for detailed studies in children with EED to better characterize the extent and impact of the condition on micronutrient use.

\section{Zinc}

Three stable isotopes of zinc $\left({ }^{70} \mathrm{Zn},{ }^{67} \mathrm{Zn}\right.$, and $\left.{ }^{68} \mathrm{Zn}\right)$ have low enough natural abundance to be useful as tracers of zinc homeostasis (57). The most commonly applied approach to measurement of zinc absorption is the "dual isotope tracer ratio" method, which involves oral administration of 1 isotope and intravenous administration of another isotope. Measurement of the ratio of the isotope enrichment in plasma or urine several days later provides a determination of the fractional absorption of zinc; multiplication of this times the amount of ingested zinc yields the amount of absorbed zinc. Oral isotope is ideally administered with all meals of the day to yield total daily absorbed zinc; administration in postabsorptive state with a standardized dose can provide estimate of absorption "capacity." Excretion of endogenously secreted zinc in the intestine, a critical aspect of zinc homeostasis, can also be estimated by the "isotope dilution" method, by determination of the ratio of the amount of an intravenously administered isotope in feces to that in urine during the same time period (58). Because the endogenous fecal zinc appears to be more reflective of host zinc status than the absorption efficiency, simplified approaches to its determination are being explored (eg, using partial instead of complete fecal collections). The size of the exchangeable $\mathrm{Zn}$ pool, a putative index of zinc status, can also be estimated by measurement of urine enrichment of an intravenously administered stable isotope. All of these approaches to zinc homeostasis have been safely applied in pregnant women, infants, and young children. Although administration and collection procedures require meticulous care and attention to detail, they have been successfully applied in many austere environments (59).

As appreciation of the complexity of EED has been increasingly recognized, it also seems likely that micronutrient requirements are higher, as a result of the impaired absorption and/or increased losses. Several approaches using zinc stable isotopes are relevant: studies comparing absorption in children with and without EED; measuring absorption from a range of doses to identify that which is high enough absorption to meet "pathophysiologic requirements"; and studies to document endogenous intestinal losses in EED. As a potential biomarker of zinc status and response to zinc interventions, exchangeable $\mathrm{Zn}$ pool is expensive, but it could usefully be measured in subsets of subjects participating in intervention trials to evaluate response to intervention and to link to functional outcomes.

\section{Iron}

The criterion standard for measuring iron absorption and bioavailability from foods or supplements, both in healthy individuals and those with malabsorption, is the iron stable-isotope technique based on erythrocyte incorporation of the stable isotope labels 14 days after intake (60). Three stable isotopes of iron are commonly used $\left({ }^{54} \mathrm{Fe},{ }^{57} \mathrm{Fe}\right.$, and $\left.{ }^{58} \mathrm{Fe}\right)$. Labeled iron compounds (eg, ferrous sulfate, ferrous fumarate, NaFeEDTA) can be prepared from isotopically enriched elemental iron. The labels are added to test meals or supplements that are fed to fasted human subjects (61). The labels mix with the total nonheme iron pool from the meal or supplement in the stomach and are mainly absorbed in the upper duodenum (62). Either within- or between-subject designs can be used. Fourteen days after the administration of the test meals, on the basis of the shift in the iron isotope ratios in the blood samples measured by mass spectrometry and the amount of iron circulating 
in the body, the amounts of the labeled iron compounds in the blood and thereby fractional absorption of the iron is calculated (63). Because these techniques involve no radioactivity, they can be used in infants and young children with no health risk $(60,64)$.

Stable iron isotopes could be used to quantify, with high precision, iron absorption and bioavailability from diets, lipidbased nutritional supplements, and/or micronutrient powders in children with EED. This would provide insight into the severity of iron malabsorption and the etiology of anemia in EED, as well as assessing changes in absorption in children recovering from EED.

\section{SINGLE CELL ISOTOPE METHODS FOR PROBING MICROBIOTA-GUT FUNCTION}

Spatially highly resolved isotope imaging emerges as an important complement to common stable isotope-labeling techniques, which essentially measure whole body or population averages that mask relevant differences between individual cells. In working toward a complete understanding of a biological system, it is important to get a more refined understanding of the contributions of its individual parts, the cells, and their interactions with each other $(65,66)$. Use of high-end microspectroscopy and secondary ion mass spectrometry instruments for stable isotope analytics allows dissection of the physiological function and metabolic heterogeneity of subpopulations of cells that constitute a tissue or the diverse species of the complex human microbiota. This is of particular importance for the gastrointestinal tract, where metabolic processes are extremely complex and dynamic because of the temporally and spatially variable presence of various diet- or host-derived substrates, and the diverse microbial populations and host cells that metabolize those substrates (67). With these single cell stable-isotope methods in hand, one can now start disassembling the manifold synergistic and antagonistic physiological interactions among individual cells of the intestinal microbiota and the host tissue and identifying key cellular populations that determine the flow of nutrients and energy to and from the host. As with any other stable isotope-labeling approach, the type of isotope (mostly ${ }^{13} \mathrm{C},{ }^{15} \mathrm{~N}$, but also ${ }^{18} \mathrm{O}$ or ${ }^{2} \mathrm{H}$ ) and substrate, and how the labeled substrate is administered determines which physiological function is being investigated. The incorporation of the isotope label into cellular components of a microbial cell is subsequently quantified with specialized instruments, such as a confocal Raman microspectroscopy, which has a lateral resolution of approximately $1 \mu \mathrm{m}$, or a NanoSIMS, a secondary ion mass spectrometer for parallel detection of up to 7 ion masses and nanoscale spatial resolution. Isotope analysis can be directly combined with fluorescence in situ hybridization for the identification of microbial cells (67). Selected applications include identification of microbes that forage on host-derived ${ }^{13} \mathrm{C} /{ }^{15} \mathrm{~N}$-labeled protein compounds (68) and use of heavy water $\left({ }^{2} \mathrm{H}_{2} \mathrm{O}\right)$ as a general marker for cellular activity (69). Although these single-cell methods were initially developed and applied in animal models, stable isotope analysis of individual cells can be readily performed on fecal samples or tissue biopsies obtained from patients that are subject to some of the more routine stable isotope tests mentioned above. Single cell analysis by Raman microspectroscopy or NanoSIMS is inherently time-consuming

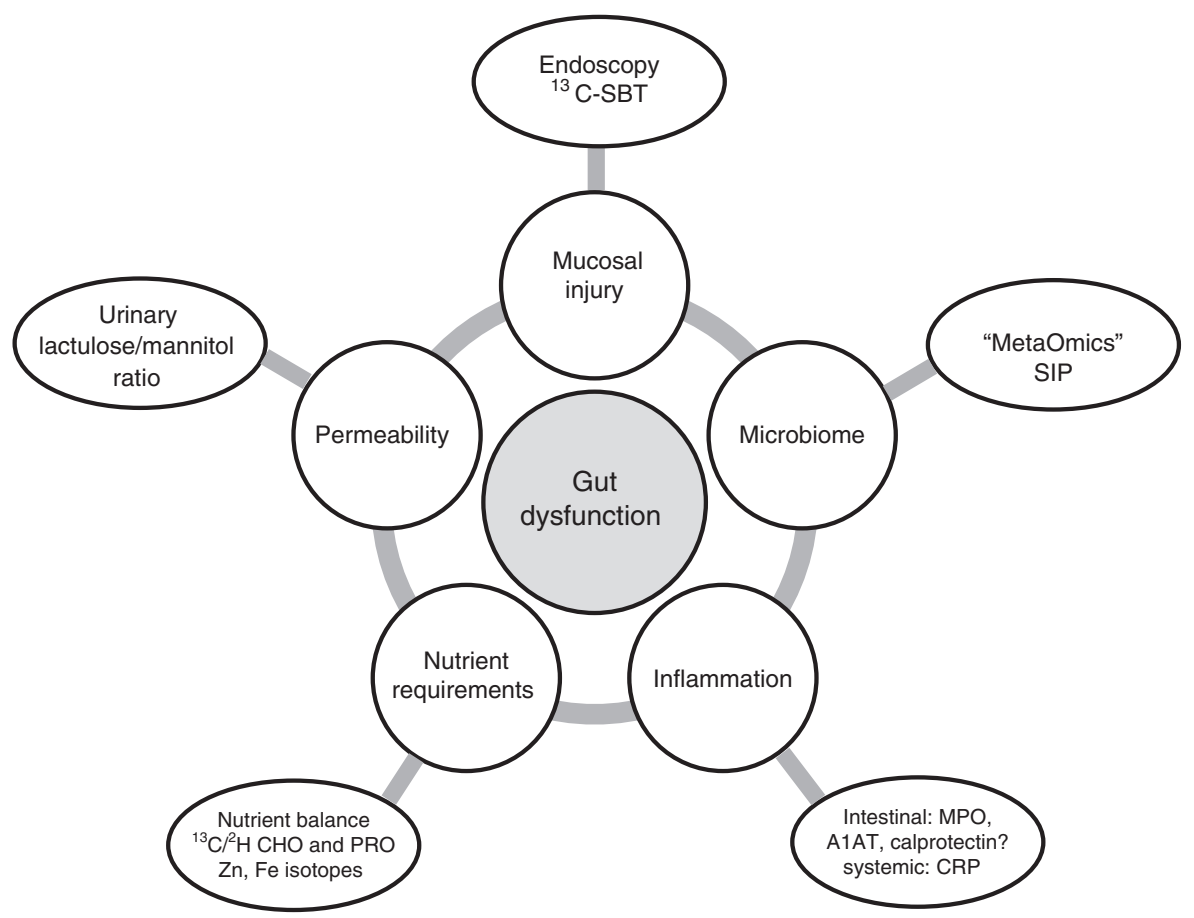

FIGURE 3. Associated with environmental enteric dysfunction (EED) are a host of functional aberrations that potentially allow for diagnostic tests in EED. Only some of these aberrations are suitable for the application of stable isotope technologies. SBT has potential to assess mucosal injury (villus atrophy). Characterizing the composition gut microbiome in EED will benefit from applying the full suite of "omics" technologies (metaomics). Characterizing the function of members of the microbiota will require stable isotope probing (SIP) and single cell technologies. Developing tools to describe nutrient requirements (carbohydrate [CHO], protein [PRO], and micronutrients [Zn, Fe]) will require development of robust stable isotope protocols. Characterizing inflammation relies on biomarkers such as $\alpha$-1-antitrypsin (AIAT), myeloperoxidase (MPO), and possibly calprotectin for intestinal inflammation and established biomarkers such as C-reactive protein (CRP) for systemic inflammation. Characterizing gut permeability relies largely on established sugar absorption/urinary excretion tests. Therefore, of significant potential for the application of stable isotope technologies is the assessment of mucosal injury, gut microbiota function, and nutrient requirements. 
and thus essentially not tailored to routine diagnostics in gastroenterology. Instead, these advanced research tools will contribute to a highresolution picture of the complex physiological processes in gastrointestinal tract, particularly into the role of individual members of the resident microbiota in EED.

\section{CHALLENGES AND FUTURE PERSPECTIVES}

The potential for stable isotope-based techniques to provide noninvasive, possibly low-cost, and field-deployable diagnostic tests in gut dysfunction is a tantalizing prospect. Significant research is still required to realize this prospect if we are to make use of stable isotopes in a setting such as EED for diagnostic or disease stratification purposes. There are challenges to overcome but the opportunities that could be realized are profound.

\section{Challenges}

Integrating high-end, high-cost mass spectrometry technologies in limited-resource settings may be seen as a significant barrier to implementing stable isotope technologies in a community setting. Solutions are beginning to emerge with field-deployable infrared-based techniques for measuring isotopic abundance in select metabolites (mainly $\mathrm{CO}_{2}$ and $\mathrm{H}_{2} \mathrm{O}$ ). Careful selection and validation of appropriate tracers for appropriate end-point measurements with robust clinical outcomes is required. Techniques for single cell investigations will remain focused in well-resourced and competent research laboratories, but because such techniques can add considerable insights into microbe and host physiology, they need to be embraced to provide a greater understanding of EED.

\section{Future Perspectives}

The adoption of stable isotope-based micronutrient bioavailability assays in intervention studies in EED will continue to add considerable insight into micronutrient use and the efficacy of fortification trials. Research using combinations of tests (stable isotopes and biomarkers) are needed to assess multiple aspects of gut dysfunction (mucosal injury, digestion, permeability/barrier function and microbiota function) simultaneously. The potential for intrinsic labeling of food to dissect how macronutrient uptake and use are affected in EED holds significant promise. These opportunities are outlined in Figure 3. Whether this integrated physiological view has the potential to allow stratification of EED into relative risk of stunted growth remains to be seen, but stratification based on biomarkers has yielded significantly improvements in the management and treatment in other contexts, for example, cancer and cardiovascular disease. Stable isotopes add essential functional measurements to the existing array of biomarkers and have significant potential to be applied in diseases where gut dysfunction has an important role.

Acknowledgments: The authors thank Professor Tom Preston, SUERC, for his constructive critical discussion in drafting this paper and for the picture of isotopic labeling of plants for human studies.

\section{REFERENCES}

1. Kosek M, Guerrant RL, Kang G, et al. Assessment of environmental enteropathy in the MAL-ED cohort study: theoretical and analytic framework. Clin Infect Dis 2014;59(suppl 4):S239-47.

2. Campbell DI, McPhail G, Lunn PG, et al. Intestinal inflammation measured by fecal neopterin in Gambian children with enteropathy: association with growth failure, Giardia lamblia, and intestinal permeability. J Pediatr Gastroenterol Nutr 2004;39:153-7.
3. Black RE, Victora CG, Walker SP, et al. Maternal and child undernutrition and overweight in low-income and middle-income countries. Lancet 2013;382:427-51.

4. Bhutta ZA, Das JK, Rizvi A, et al. Evidence-based interventions for improvement of maternal and child nutrition: what can be done and at what cost? Lancet 2013;382:452-77.

5. Trehan I, Kelly P, Shaikh N, et al. New insights into environmental enteric dysfunction. Arch Dis Child 2016;101:741-4.

6. Keusch GT, Denno DM, Black RE, et al. Environmental enteric dysfunction: pathogenesis, diagnosis, and clinical consequences. Clin Infect Dis 2014;59(suppl 4):S207-12.

7. Romagnuolo J, Schiller D, Bailey RJ. Using breath tests wisely in a gastroenterology practice: an evidence-based review of indications and pitfalls in interpretation. Am J Gastroenterol 2002;97:1113-26.

8. Klein PD, Klein ER. Applications of stable isotopes to pediatric nutrition and gastroenterology: measurement of nutrient absorption and digestion using 13C. J Pediatr Gastroenterol Nutr 1985;4:9-19.

9. Leal YA, Flores LL, Fuentes-Panana EM, et al. 13C-urea breath test for the diagnosis of Helicobacter pylori infection in children: a systematic review and meta-analysis. Helicobacter 2011;16:327-37.

10. Dror G, Muhsen K. Helicobacter pylori infection and children's growth: an overview. J Pediatr Gastroenterol Nutr 2016;62:e48-59.

11. Butler RN. Measuring tools for gastrointestinal toxicity. Curr Opin Support Palliat Care 2008;2:35-9.

12. Butler RN. Non-invasive tests in animal models and humans: a new paradigm for assessing efficacy of biologics including prebiotics and probiotics. Curr Pharm Des 2008;14:1341-50.

13. Nguyen NQ, Chapman M, Fraser RJ, et al. Long-standing type II diabetes mellitus is not a risk factor for slow gastric emptying in critically ill patients. Intensive Care Med 2006;32:1365-70.

14. Omari TI, Benninga MA, Sansom L, et al. Effect of baclofen on esophagogastric motility and gastroesophageal reflux in children with gastroesophageal reflux disease: a randomized controlled trial. J Pediatr 2006;149:468-74.

15. Urita Y, Hike K, Torii N, et al. Efficacy of lactulose plus 13C-acetate breath test in the diagnosis of gastrointestinal motility disorders. $J$ Gastroenterol 2002;37:442-8.

16. Perman JA. Clinical application of breath hydrogen measurements. Can J Physiol Pharmacol 1991;69:111-5.

17. Koetse HA, Stellaard F, Bijleveld CM, et al. Non-invasive detection of low-intestinal lactase activity in children by use of a combined $13 \mathrm{CO}_{2} /$ $\mathrm{H}_{2}$ breath test. Scand J Gastroenterol 1999;34:35-40.

18. Misselwitz B, Pohl D, Fruhauf H, et al. Lactose malabsorption and intolerance: pathogenesis, diagnosis and treatment. United European Gastroenterol J 2013;1:151-9.

19. Clarke JM, Pelton NC, Bajka BH, et al. Use of the 13C-sucrose breath test to assess chemotherapy-induced small intestinal mucositis in the rat. Cancer Biol Ther 2006;5:34-8.

20. Pelton NS, Tivey DR, Howarth GS, et al. A novel breath test for the noninvasive assessment of small intestinal mucosal injury following methotrexate administration in the rat. Scand J Gastroenterol 2004;39:1015-6.

21. Tooley KL, Saxon BR, Webster J, et al. A novel non-invasive biomarker for assessment of small intestinal mucositis in children with cancer undergoing chemotherapy. Cancer Biol Ther 2006;5:1275-81.

22. Tran CD, Hawkes J, Graham RD, et al. Zinc-fortified oral rehydration solution improved intestinal permeability and small intestinal mucosal recovery. Clin Pediatr (Phila) 2015;54:676-82.

23. Yazbeck R, Howarth GS, Borges L, et al. Non-invasive detection of a palifermin-mediated adaptive response following chemotherapy-induced damage to the distal small intestine of rats. Cancer Biol Ther 2011;12:399-406.

24. Ritchie BK, Brewster DR, Davidson GP, et al. 13C-sucrose breath test: novel use of a noninvasive biomarker of environmental gut health. Pediatrics 2009;124:620-6.

25. Ritchie BK, Brewster DR, Tran CD, et al. Efficacy of Lactobacillus GG in aboriginal children with acute diarrhoeal disease: a randomised clinical trial. J Pediatr Gastroenterol Nutr 2010;50:619-24.

26. Schoeller DA. 2001 uses of stable isotopes in the assessment of nutrient status and metabolism. Forum Nutr 2003;56:310-1.

27. Hiele M, Ghoos Y, Rutgeerts P, et al. Measurement of the rate of assimilation of oligo- and polysaccharides by $13 \mathrm{CO} 2$ breath tests and isotope ratio mass spectrometry. Biomed Environ Mass Spectrom 1988;16:133-5. 
28. Tanis AA, Rietveld T, Wattimena JL, et al. The $13 \mathrm{CO} 2$ breath test for liver glycogen oxidation after 3-day labeling of the liver with a naturally 13C-enriched diet. Nutrition 2003;19:432-7.

29. Jonderko K, Spinkova M, Kaminska M, et al. Ability to digest starch assessed noninvasively with a $13 \mathrm{CO} 2$ breath test - comparison of results obtained in two groups of different age. Med Sci Monit 2009; 15:CR128-33.

30. Seal CJ, Daly ME, Thomas LC, et al. Postprandial carbohydrate metabolism in healthy subjects and those with type 2 diabetes fed starches with slow and rapid hydrolysis rates determined in vitro. $\mathrm{Br} \mathrm{J}$ Nutr 2003;90:853-64.

31. Weaver LT, Dibba B, Sonko B, et al. Measurement of starch digestion of naturally $13 \mathrm{C}$-enriched weaning foods, before and after partial digestion with amylase-rich flour, using a 13 C breath test. Br J Nutr 1995;74:5317.

32. Korach-Andre M, Roth H, Barnoud D, et al. Glucose appearance in the peripheral circulation and liver glucose output in men after a large $13 \mathrm{C}$ starch meal. Am J Clin Nutr 2004;80:881-6.

33. Vinoy S, Normand S, Meynier A, et al. Cereal processing influences postprandial glucose metabolism as well as the GI effect. J Am Coll Nutr 2013;32:79-91.

34. Robertson MD, Livesey G, Mathers JC. Quantitative kinetics of glucose appearance and disposal following a 13C-labelled starch-rich meal: comparison of male and female subjects. Br J Nutr 2002;87:569-77.

35. Boets E, Deroover L, Houben E, et al. Quantification of in vivo colonic short chain fatty acid production from inulin. Nutrients 2015;7:891629.

36. Lifschitz CH, Grusak MA, Butte NF. Carbohydrate digestion in humans from a beta-glucan-enriched barley is reduced. J Nutr 2002;132:25936.

37. Ghosh S, Suri D, Uauy R. Assessment of protein adequacy in developing countries: quality matters. Br J Nutr 2012;108(suppl 2):S77-87.

38. Semba RD, Shardell M, Sakr Ashour FA, et al. Child stunting is associated with low circulating essential amino acids. EBioMedicine 2016;6:246-52.

39. Elango R, Levesque C, Ball RO, et al. Available versus digestible amino acids: new stable isotope methods. Br J Nutr 2012;108(suppl 2):S30614.

40. Tome D. Criteria and markers for protein quality assessment: a review. Br J Nutr 2012;108(suppl 2):S222-9.

41. Bos C, Mahe S, Gaudichon C, et al. Assessment of net postprandial protein utilization of $15 \mathrm{~N}$-labelled milk nitrogen in human subjects. $\mathrm{Br} \mathrm{J}$ Nutr 1999;81:221-6.

42. Mariotti F, Mahe S, Benamouzig R, et al. Nutritional value of [15N]-soy protein isolate assessed from ileal digestibility and postprandial protein utilization in humans. J Nutr 1999;129:1992-7.

43. Juillet B, Saccomani MP, Bos C, et al. Conceptual, methodological and computational issues concerning the compartmental modeling of a complex biological system: postprandial inter-organ metabolism of dietary nitrogen in humans. Math Biosci 2006;204:282-309.

44. Elango R, Humayun MA, Ball RO, et al. Protein requirement of healthy school-age children determined by the indicator amino acid oxidation method. Am J Clin Nutr 2011;94:1545-52.

45. Pennings B, Groen B, de Lange A, et al. Amino acid absorption and subsequent muscle protein accretion following graded intakes of whey protein in elderly men. Am J Physiol Endocrinol Metab 2012; 302:E992-9.

46. Pennings B, Groen BB, van Dijk JW, et al. Minced beef is more rapidly digested and absorbed than beefsteak, resulting in greater postprandial protein retention in older men. Am J Clin Nutr 2013;98:121-8.

47. Engelen MP, Com G, Anderson PJ, et al. New stable isotope method to measure protein digestibility and response to pancreatic enzyme intake in cystic fibrosis. Clin Nutr 2014;33:1024-32.
48. Tome D, Jahoor F, Kurpad A, et al. Current issues in determining dietary protein quality and metabolic utilization. Eur J Clin Nutr 2014; 38:537-8.

49. NATIONS FAAOOTU. FAO Research Approaches and Methods for Evaluating the Protein Quality of Human Foods.NATIONS FAAOOTU; 2014:ISBN 978-92-5-108695-7.

50. Kasumov T, Ilchenko S, Li L, et al. Measuring protein synthesis using metabolic (2)H labeling, high-resolution mass spectrometry, and an algorithm. Anal Biochem 2011;412:47-55.

51. Claydon AJ, Thom MD, Hurst JL, et al. Protein turnover: measurement of proteome dynamics by whole animal metabolic labelling with stable isotope labelled amino acids. Proteomics 2012;12:1194-206.

52. MacDonald AJ, Small AC, Greig CA, et al. A novel oral tracer procedure for measurement of habitual myofibrillar protein synthesis. Rapid Commun Mass Spectrom 2013;27:1769-77.

53. Ventrucci M, Cipolla A, Ubalducci GM, et al. 13C labelled cholesteryl octanoate breath test for assessing pancreatic exocrine insufficiency. Gut 1998;42:81-7.

54. Amarri S, Harding M, Coward WA, et al. 13Carbon mixed triglyceride breath test and pancreatic enzyme supplementation in cystic fibrosis. Arch Dis Child 1997;76:349-51.

55. Nakamura H, Murakami Y, Morifuji M, et al. Analysis of fat digestive and absorptive function after subtotal gastrectomy by a 13C-labeled mixed triglyceride breath test. Digestion 2009;80:98-103.

56. Chavez-Jauregui RN, Mattes RD, Parks EJ. Dynamics of fat absorption and effect of sham feeding on postprandial lipema. Gastroenterology 2010;139:1538-48.

57. Krebs NF, Miller L, Naake V, et al. The use of stable isotope techniques to assess zinc metabolism 1995;6:292-301.

58. Krebs NF, Miller LV, Hambidge KM. Zinc deficiency in infants and children: a review of its complex and synergistic interactions. Paediatr Int Child Health 2014;34:279-88.

59. Miller LV, Hambidge KM, Krebs NF. Zinc absorption is not related to dietary phytate intake in infants and young children based on modeling combined data from multiple studies. J Nutr 2015;145:1763-9.

60. Kastenmayer P, Davidsson L, Galan P, et al. A double stable isotope technique for measuring iron absorption in infants. $\mathrm{Br} J$ Nutr 1994;71:411-24.

61. Troesch B, Egli I, Zeder C, et al. Fortification iron as ferrous sulfate plus ascorbic acid is more rapidly absorbed than as sodium iron EDTA but neither increases serum nontransferrin-bound iron in women. $J$ Nutr 2011;141:822-7.

62. Zimmermann MB, Hurrell RF. Nutritional iron deficiency. Lancet 2007;370:511-20.

63. Troesch B, Egli I, Zeder C, et al. Optimization of a phytase-containing micronutrient powder with low amounts of highly bioavailable iron for in-home fortification of complementary foods. Am J Clin Nutr 2009;89:539-44.

64. Zimmermann MB, Harrington M, Villalpando S, et al. Nonheme-iron absorption in first-degree relatives is highly correlated: a stable-isotope study in mother-child pairs. Am J Clin Nutr 2010;91:802-7.

65. de Souza N. Supplement on single-cell analysis. Nat Meth 2011;8:S1-1.

66. de Souza N. Single-cell methods. Nat Meth 2012;9:35-135.

67. Stecher B, Berry D, Loy A. Colonization resistance and microbial ecophysiology: using gnotobiotic mouse models and single-cell technology to explore the intestinal jungle. FEMS Microbiol Rev 2013;37:793-829.

68. Berry D, Stecher B, Schintlmeister A, et al. Host-compound foraging by intestinal microbiota revealed by single-cell stable isotope probing. Proc Natl Acad Sci USA 2013;110:4720-5.

69. Berry D, Mader E, Lee TK, et al. Tracking heavy water (D2O) incorporation for identifying and sorting active microbial cells. Proc Natl Acad Sci USA 2015;112:E194-203. 